\title{
Correction to: Increased unfolded protein responses caused by MED17 mutations
}

\author{
Takeshi Terabayashi ${ }^{1}$ - Satoru Hashimoto ${ }^{2,3}$
}

Received: 23 August 2021 / Accepted: 23 August 2021 / Published online: 13 September 2021

○) Springer-Verlag GmbH Germany, part of Springer Nature 2021

\section{Correction to: Neurogenetics \\ https://doi.org/10.1007/s10048-021-00661-6}

There was a factual error regarding one of the figures in Supplementary Figure S3, and we have replaced it. There is no mistake in the corresponding legend.

The original article can be found online at https://doi.org/10.1007/ s10048-021-00661-6.

Satoru Hashimoto

shashimoto@oita-u.ac.jp

1 Department of Pharmacology, Faculty of Medicine, Oita University, Oita 879-5593, Japan

2 Faculty of Science and Technology, Oita University, 700 Dannoharu, Oita 870-1192, Japan

3 Clinical Research Center for Diabetes, Tokushima University Hospital, Tokushima 770-8503, Japan 
Fig. S3 Irrelevant splicing of MED17 transcripts from c.1013-5A > G mutation allele a. Splicing pattern of exon-exon junction of $M E D 17$ transcripts having c.1013-5A $>\mathrm{G}$ mutation. WT mRNA should be produced by accurate splicing, while four nucleotides would be inserted between exon 6 and 7 by irrelevant splicing. b. Experimental design of restriction fragment length polymorphism (RFLP) assay. cDNA reverse-transcribed from WT and c. 1013-5A $>\mathrm{G}$ (accurate splicing) $M E D 17$ mRNA were digested to two DNA fragments by Mun I restriction enzyme, while c.1484 $\mathrm{T}>\mathrm{G}$ was not digested. DNA fragments from c. 1013-5A > G (irrelevant splicing) was not determined without $\mathrm{CHX}$ because of the NMD. c. RFLP assay showed the absence of digested two DNA fragments in patients' cells indicating that predicted WT MED17 mRNA transcribed from c. 1013-5A $>\mathrm{G}$ allele was barely expressed.
MED17 c. 1013-5A > G allele

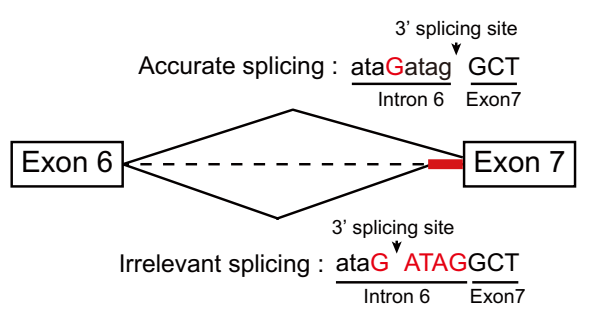

b

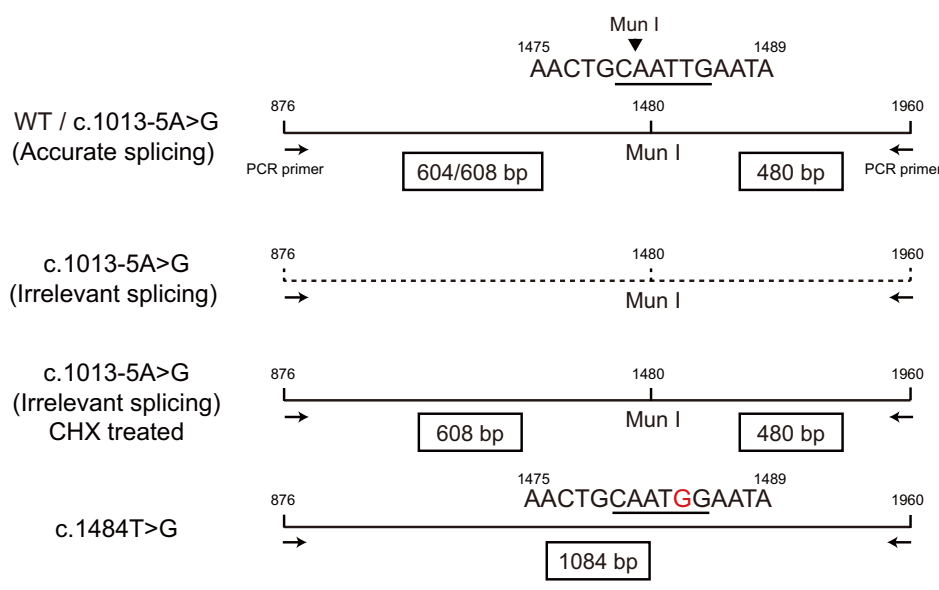

DNA fragment after Munl digestion $604 / 608$ bp and 480 bp

Less detectable due to NMD

$608 \mathrm{bp}$ and $480 \mathrm{bp}$

1084 bp

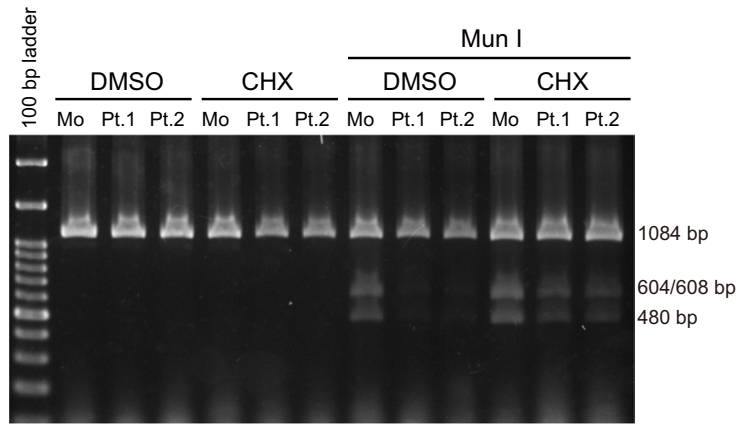

Publisher's note Springer Nature remains neutral with regard to jurisdictional claims in published maps and institutional affiliations. 